\title{
Spermatophores and Plug Substance of the Marine Shrimp Trachypenaeus similis (Crustacea: Decapoda: Penaeidae): Formation in the Male Reproductive Tract and Disposition in the Inseminated Female
}

\author{
RAYMOND T. BAUER AND LIN JUN MIN \\ Department of Biology, University of Southwestern Louisiana, Lafayette, Louisiana, 70504
}

\begin{abstract}
Sperm are packaged into many small spermatophores of variable size in the median vas deferens (MVD) of the male. A substance is intermixed with sperm in the proximal coils of the MVD, separating groups of sperm that will be ejaculated as spermatophores. Most of the ejaculatory duct is occupied by a chamber filled with a transparent, viscous fluid termed the "plug substance." When males are artificially ejaculated, spermatophores are emitted, followed by plug substance that quickly solidifies. This latter material fills and stoppers a space on the female, the median pocket, which serves as an antechamber to the apertures of the internalized seminal receptacles, where sperm from ruptured spermatophores are stored. The slit-like openings to the receptacles are functionally divided into a posterior aperture, stoppered by plug substance after insemination, a closed mid-section, and an anterior exit for sperm release during spawning.

Direct insemination by an everted male gonopore is considered more likely than transmission of spermatophores and plug substance via the male gonopod (petasma). In addition to its hypothesized roles during insemination and sperm release, the mass of plug substance (mating plug) may act as a paternity assurance device that prevents subsequent inseminations by other males.
\end{abstract}

\section{Introduction}

There is considerable variation in the form and complexity of materials transferred from the male to the female during insemination in penaeoid shrimps (Decapoda: Penaeoidea) (Bauer, 1991). Sperm may be packaged in

Received 18 December 1992; accepted 14 July 1993.

Contribution No. 40 of the USL Center for Crustacean Research. structurally complicated spermatophores composed of an assortment of accessory substances secreted in the male reproductive tract. The most complex spermatophores are those attached externally to the genital area, or thelycum, of the female, as in the white shrimp, Penaeus setiferus, and other species of the subgenus Litopenaeus (Pérez Farfante, 1975; Bauer and Cash, 1991; Chow et al., 1991). In contrast, in the rock shrimps, Sicyonia spp., sperm in a seminal fluid are produced by the male and transferred to, and stored in, internal seminal receptacles of the female (Clark et al., 1984; Pérez Farfante, 1985; Bauer, 1991, 1992). Other penaeoid shrimps, such as Trachypenaeus spp., show intermediate degrees of spermatophore complexity and of internalization of sperm storage (Burkenroad, 1934; Heldt, 1938a, b; Hudinaga, 1941; Malek and Bawab, 1974a, b; Pérez Farfante, 1971, 1982; Champion, 1987; Bauer and Cash, 1991).

Detailed knowledge of the nature and formation of spermatophores and associated substances and of their disposition in the inseminated female is essential to an understanding of the mechanics of insemination, sperm storage, and sperm release during fertilization. In addition, characters associated with spermatophores and the insemination morphology of the male and female are important in analyses of the evolutionary relationships among taxa of penaeoid shrimps, as well as to an evolutionary interpretation of their mating systems (Bauer, 1991).

Observations on the spermatophores, seminal receptacles, and thelyca of various species of Trachypenaeus (Penaeidae) have been made by Andrews (1911), Burkenroad (1934), Kubo (1949), Pérez Farfante (1971), and Bauer (1991). The structure of the Trachypenaeus sper- 
matophore is somewhat unusual among penaeoids in that sperm are packaged into numerous small spherical bundles (Burkenroad, 1934; Bauer, 1991), superficially very similar to spermatophores produced by male brachyuran crabs (Spalding, 1942; Cronin, 1947; Beninger et al., 1988; Hinsch, 1988). However, little detailed information on Trachypenaeus spp. is available on the formation and structure of spermatophores, on a male accessory substance that plugs or seals the female seminal receptacles, or on the placement of sperm and "plug substance" in the thelyca and seminal receptacles of females.

In this report, we describe in Trachypenaeus similis (Smith) (1) the structure and formation of spermatophores and the plug substance in the male reproduction tract, and (2) the thelycum/seminal receptacle system of the female, especially the placement of sperm and plug substance therein. We discuss alternative hypotheses on the mechanics of insemination, based both on these morphological observations and on observations from artificial ejaculation of living males. We make comparisons of spermatophores and insemination morphology of T. similis with that of other penaeoid shrimps and other decapod taxa.

\section{Materials and Methods}

Specimens of Trachypenaeus similis were obtained by bottom trawling at night in various locations in the northern Gulf of Mexico. Some material used for dissection and histology was obtained on cruises in 1987 and 1990 within an area at $28-29^{\circ} \mathrm{N}$ latitude and $88-94^{\circ} \mathrm{W}$ longitude. From 1989 to 1992 , other specimens were trawled from the Mississippi Sound, just off the northwest end of Horn Island, Mississippi. Observations on living shrimps were taken on specimens collected from the Horn Island location and transported in oxygen-saturated water within sealed plastic bags to recirculating seawater facilities at the University of Southwestern Louisiana.

Segments of or entire reproductive tracts of 33 males and the thelycum/seminal receptacle area of 30 females were prepared for histology or paraffin carving. Live specimens, anesthetized with chilling when possible, were injected with and initially preserved in Davidson's solution (Shaw and Battle, 1957). Within a few days of fixation, specimens were washed in running water for $1-2 \mathrm{~h}$ and were then taken through a graduated series of alcohol changes $(25 \%, 35 \%, 50 \%, 70 \%)$ with final storage in $70 \%$ ethyl alcohol. Standard alcohol dehydration and toluene infiltration were used to prepare dissected material for embedding in a compound of paraffin and plastic polymers (Galigher and Kozloff, 1971). Sections were stained with Mallory's Triple Stain, using the variation in which sections are rinsed with $1 \%$ phosophotungstic acid after staining in acid fuchsin and prior to staining in aniline blue-orange G mixture (Galigher and Kozloff, 1971). In paraffin carving, material was sectioned to a desired location, deparaffined in toluene, gradually re-infiltrated with $100 \%$ ethyl alcohol, and prepared for scanning electron microscopy (SEM) by critical-point drying with carbon dioxide and sputter coating with a $10-20 \mathrm{~nm}$ thickness of gold/palladium. Methods for SEM of external morphology are described in Bauer (1987).

Living shrimps were maintained on water tables with recirculating seawater. Adult females were isolated individually and checked daily for molting. Upon molting, females cast off stored sperm and other male products from previous inseminations, and several such females were preserved for SEM 2-3 days after molting. Exuviae of many females $(>50)$ were collected and preserved for later examination. Living males, held ventral side up immersed in seawater in a dish under a stereomicroscope, were artificially ejaculated by squeezing both sides of the posterior cephalothorax at the level of the gonopores with a pair of fine forceps.

Ejaculated spermatophores or fresh dissections of ejaculatory ducts were deposited in a drop of seawater on plastic coverslips coated with polylysine (Mazia et al., 1975). After 5-10 minutes to allow spermatophores and sperm from spontaneously ruptured spermatophores to adhere to coverslip surfaces, coverslips were gently immersed in $4 \%$ seawater formalin in petri dishes for fixation of material. Washes with distilled water and a standard alcohol series were made by gently pipetting solutions out of and into the petri dishes. The coverslips with adhering material were then prepared for SEM as described above.

\section{Results}

\section{Gross morphology of the male reproductive tract}

The male reproductive system, situated above the gut and hepatopancreas in the posterior half of the cephalothorax, consists of paired testes, vasa deferentia, and ejaculatory ducts (Fig. 1). The testis on each side is composed of 5-6 lobes, the first with an anterior elongation, and a posterior extension inserted among the coils of the median vas deferens. In freshly sacrificed specimens, a testicular lobe can be teased apart, revealing that each lobe is composed of a single, highly convoluted seminiferous tubule.

The vas deferens can be divided on the basis of gross morphology into proximal, median, and distal portions (Fig. 1). The structure we identify as the proximal vas deferens (PVD) is a very fine duct, difficult to identify in, and illustrate from, gross dissections but apparent in serial sections (Fig. 2). A PVD runs along the mesial edges of the testicular lobes, merging into the proximal part of the median vas deferens at the posterior end of the testis (Fig. 1). The connections between the seminiferous tubules and the PVD were not clearly observed. We refer to the highly 


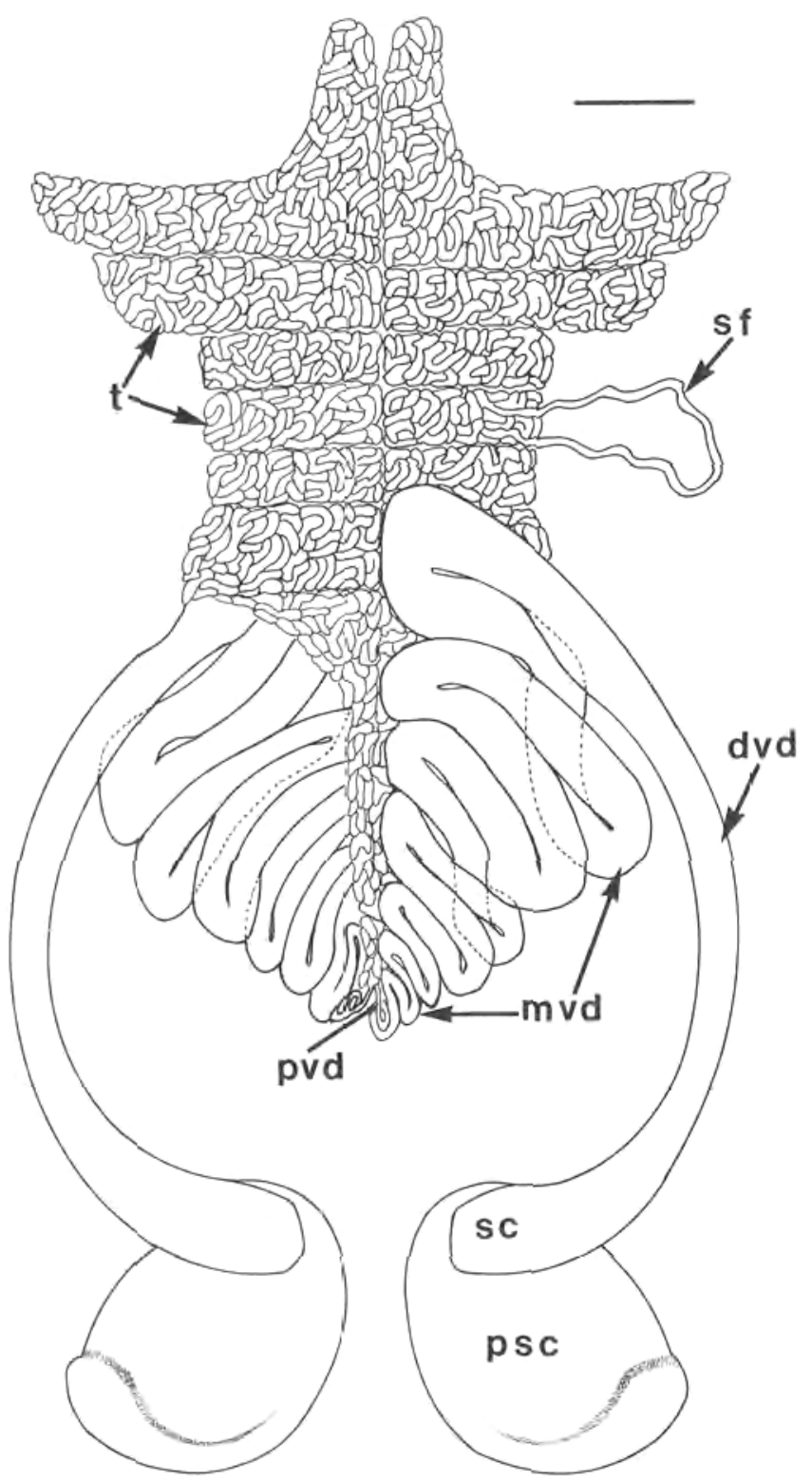

Figure 1. Diagram of male reproductive tract of Trachypenaeus similis, dorsal view. Testicular tissue covering coils of right median vas deferens (MVD) is not illustrated. In most preserved specimens, the coils of the MVD are usually bunched into a more compact, tangled mass than illustrated in this diagram, with the distal (anterior) coils somewhat below the more proximal (posterior) ones. dvd, distal vas deferens; mvd, coils of median vas deferens; psc, plug substance chamber of ejaculatory duct; pvd, posterior end of proximal vas deferens merging into the median vas deferens; sc, spermatophore chamber of ejaculatory duct; sf, seminiferous tubule; $\mathrm{t}$, testicular lobes. Scale bar $=1 \mathrm{~mm}$

coiled portion of the vas as the median vas deferens (MVD), which lies under the posterior part of the testis (Fig. 1). Each MVD begins posteriorly, gradually increasing in diameter distally (anteriorly). The distal vas deferens (DVD) is defined as the long, curved, uncoiled portion of the vas that lies outside of the testicular-MVD mass. Each
DVD extends to the body wall of the last cephalothoracic segment, descending down ventrally to join the ejaculatory duct in the floor of the cephalothorax.

The ejaculatory duct has two distinct but confluent chambers (Fig. 1). The spermatophore chamber (SC), an extension of the DVD, is located anteriorly, opening mesially to the outside through the gonopore, situated externally between the mesial edge of the coxa of the fifth (most posterior) pereiopod and the sternum of the male. A large chamber, the "plug substance chamber" (PSC), lies posterior to the SC. The PSC is partially divided into two regions, which are continuous mesially. The two chambers of the ejaculatory duct are quite distinct in color and transparency, with the SC bright white or opaque, and the PSC clear or transparent with a yellow tint in living and preserved specimens, respectively.

\section{Spermatophore structure and formation}

When males are artificially ejaculated, a short cord composed of many spermatophores is emitted from the gonopores. The spherical spermatophores, which separate from each other in seawater within seconds to minutes, are quite variable in size (Fig. 6). Each spermatophore is composed of a group of sperm cells surrounded by a thin film or pellicle (Figs. 3, 4). Undisturbed spermatophores remain intact in seawater for at least an hour, but rupture easily when moved about or handled, releasing the sperm cells (Figs. 3, 4, 7). Many sperm cells were examined with SEM and light microscopy, and all showed the same external structure of a main body, cap, spike, and a long, delicate filament extending away from the main body (Fig. 7).

A striking decrease in the thickness of the epithelium lining the MVD from the proximal to distal coils (Fig. 5) coincides with spermatophore formation. In the most proximal coils of the MVD, the epithelium is composed of large cuboidal to columnar cells with distinct nuclei (Fig. 2), and the lumens of these coils are filled with a solid mass of sperm (Figs. 2, 5, 8). In this region, a material, termed here MVD substance, which apparently forms the spermatophore pellicle, first appears (Fig. 8). In sections stained with Mallory's Triple Stain, the MVD substance appears a pale blue when viewed with light microscopy. The MVD substance increases in volume more distally in the MVD, where it intermingles with sperm, surrounding and separating out groups or packets, which are incipient spermatophores (Fig. 9).

In the DVD, the epithelium is quite flattened and thin, as in the distal-most part of the MVD (Fig. 5), and the lumen is filled with sperm packets surrounded by MVD substance (Fig. 12). When the wall of the DVD is stripped away to expose the underlying contents, the separate, variably sized groups of sperm are exposed, 

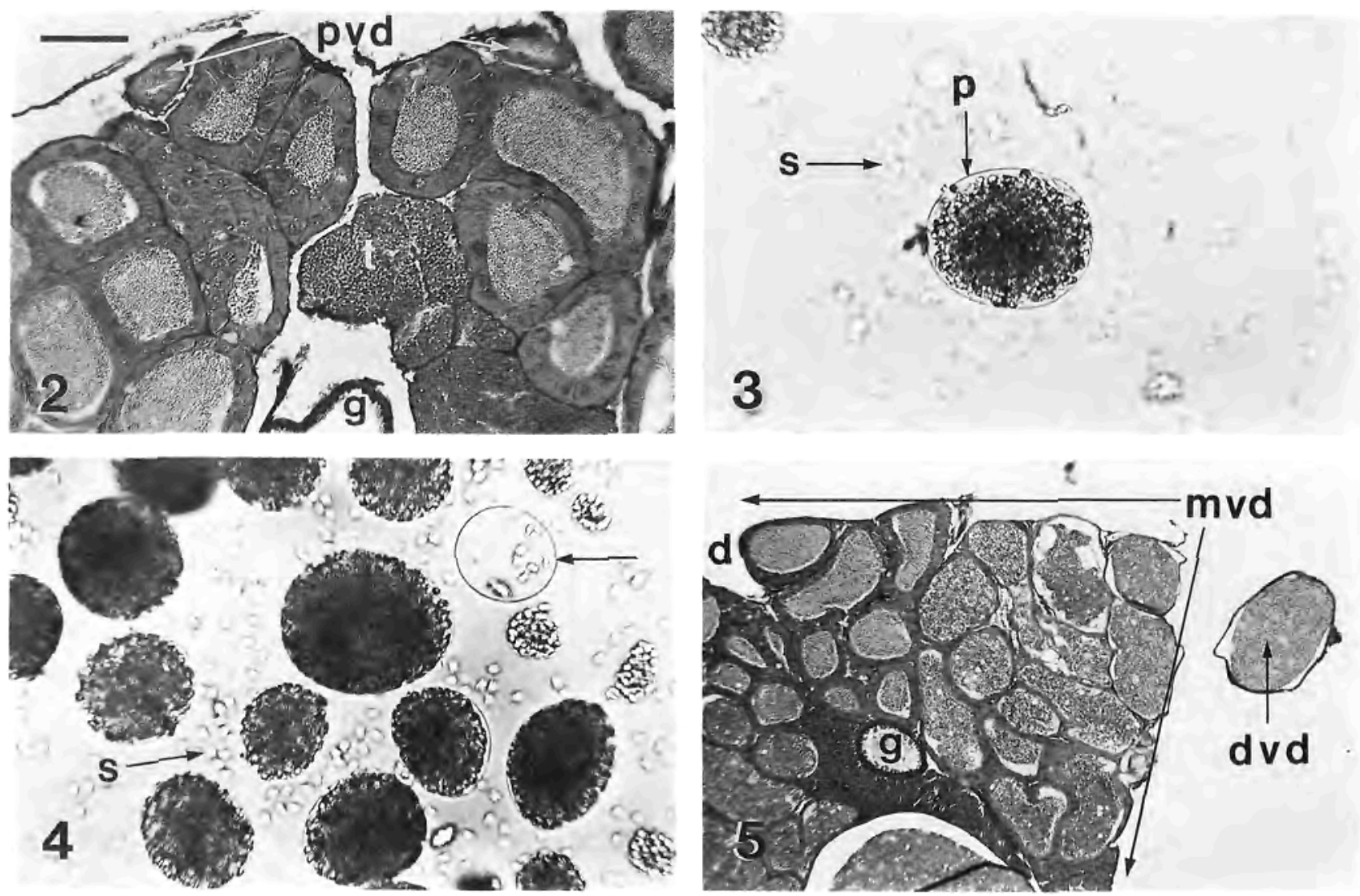

Figure 2. Cross section through proximal (posterior) coils of median vas deferens of Trachypenaeus similis, showing left and right proximal vasa deferentia ( $\mathrm{pvd}$ ) dorsal to coils. $\mathrm{g}$, gut; $\mathrm{t}$, tissue of posterior extension of testes.

Figure 3. Single spermatophore showing pellicle (p) surrounding group of sperm. s, sperm free in water from ruptured spermatophores.

Figure 4. Group of spermatophores including one (unlabeled arrow) in which most sperm have escaped, leaving behind a largely unbroken pellicle. s, sperm from ruptured spermatophores.

Figure 5. Cross section through coils of median vas deferens (bordered by arrows labeled mvd) of one side approximately halfway along its length, showing proximal-to-distal decrease in duct wall thickness. Note thin-walled distal vas deferens (dvd) lateral to median vas deferens. d, dorsal side of section; $\mathrm{g}$, gut. Scale bar in Figure 2 represents $800 \mu \mathrm{m}$ in Figure 2, $300 \mu \mathrm{m}$ in Figures 3, 4, and $2 \mathrm{~mm}$ in Figure 5.

coated by MVD substance (Fig. 10). The MVD substance surrounding the sperm packets is completely continuous with that of adjacent groups of sperm (Figs. 10, 12).

\section{Internal anatomy of and materials in the ejaculatory duct}

Sections through the ejaculatory duct show that the spermatophore chamber (SC) is a continuation of the thinwalled DVD, filled with sperm packets separated by MVD substance (Figs. 11, 13). A large duct, the "plug substance" chamber (PSC), occupies the bulk of the ejaculatory duct (ED) (Figs. 1, 11) and is lined with a well-developed epithelium (Figs. 11, 14). The PSC is partially subdivided with a posterior chamber (Figs. 1, 14), which is confluent mesially with the main PSC chamber. The PSC and the SC are separated on the mesial side of the ED (Fig. 11), but laterally, in the area of the gonopore, the two chambers are continuous (Fig. 15). Plug substance intrudes into the mass of sperm packets above the posterior gonopore area (Fig. 15), but more anteriorly sperm packets fill the space over the gonopore (Fig. 13).

The interior of the PSC is filled with a material (Figs. 11,14), appearing a reddish purple when stained with Mallory's Triple Stain and viewed with light microscopy, which is very hard and difficult to section in paraffin-embedded material. When living males are artificially ejaculated, the contents of the PSC flow out of the gonopore after emission of a cord of spermatophores. The PSC material is a viscous, clear, adhesive fluid when first leaving the gonopore. Within 

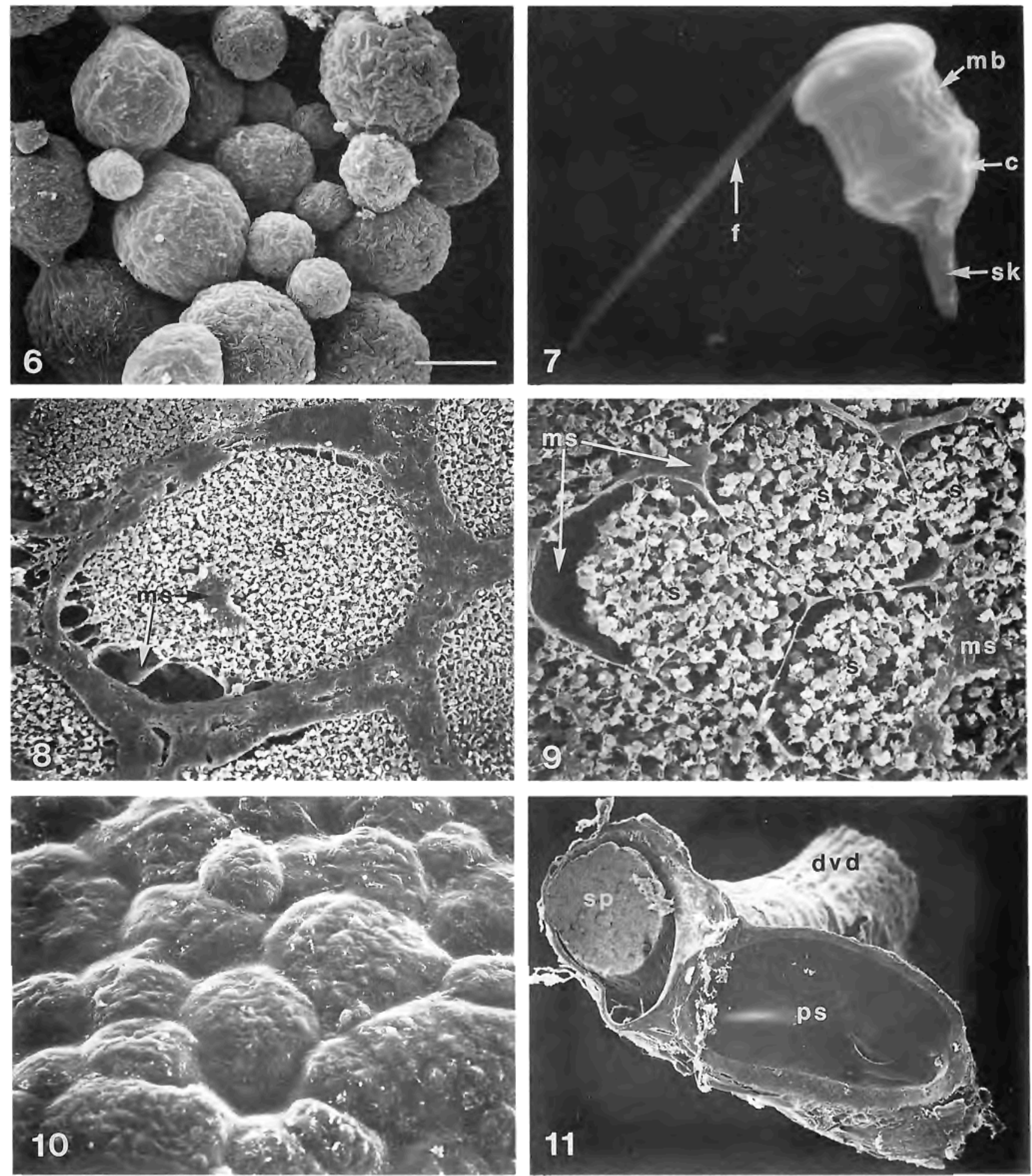

Figure 6. Spermatophores of Trachypenaeus similis, showing variation in size.

Figure 7. Sperm cell of $T$. similis. c, cap; f, filament; mb, main body; sk, spike,

Figure 8. Section through median vas deferens near proximal end, showing appearance of MVD substance (ms) just inside epithelium and inside solid mass of sperm. s, sperm mass.

Figure 9. Section through four adjoining sperm packets separated by MVD substance ( $\mathrm{ms}$ ) in distal (anteriori end of median vas deferens. s, sperm mass.

Figure 10. View of outer surface of spermatophores exposed when wall of distal vas deferens was dissected away. Note continuity of MVD substance among spermatophores.

Figure 11. Sagittal section taken on mesial side of right ejaculatory duct. dvd, distal vas deferens; ps, plug substance in plug substance chamber; sp, mass of spermatophores in spermatophore chamber. Scale bar in Figure 6 represents $33 \mu \mathrm{m}$ in Figure $6,1.4 \mu \mathrm{m}$ in Figure $7.35 \mu \mathrm{m}$ in Figure $8.18 \mu \mathrm{m}$ in Figures 9 and 10 , and $216 \mu \mathrm{m}$ in Figure 11 . 

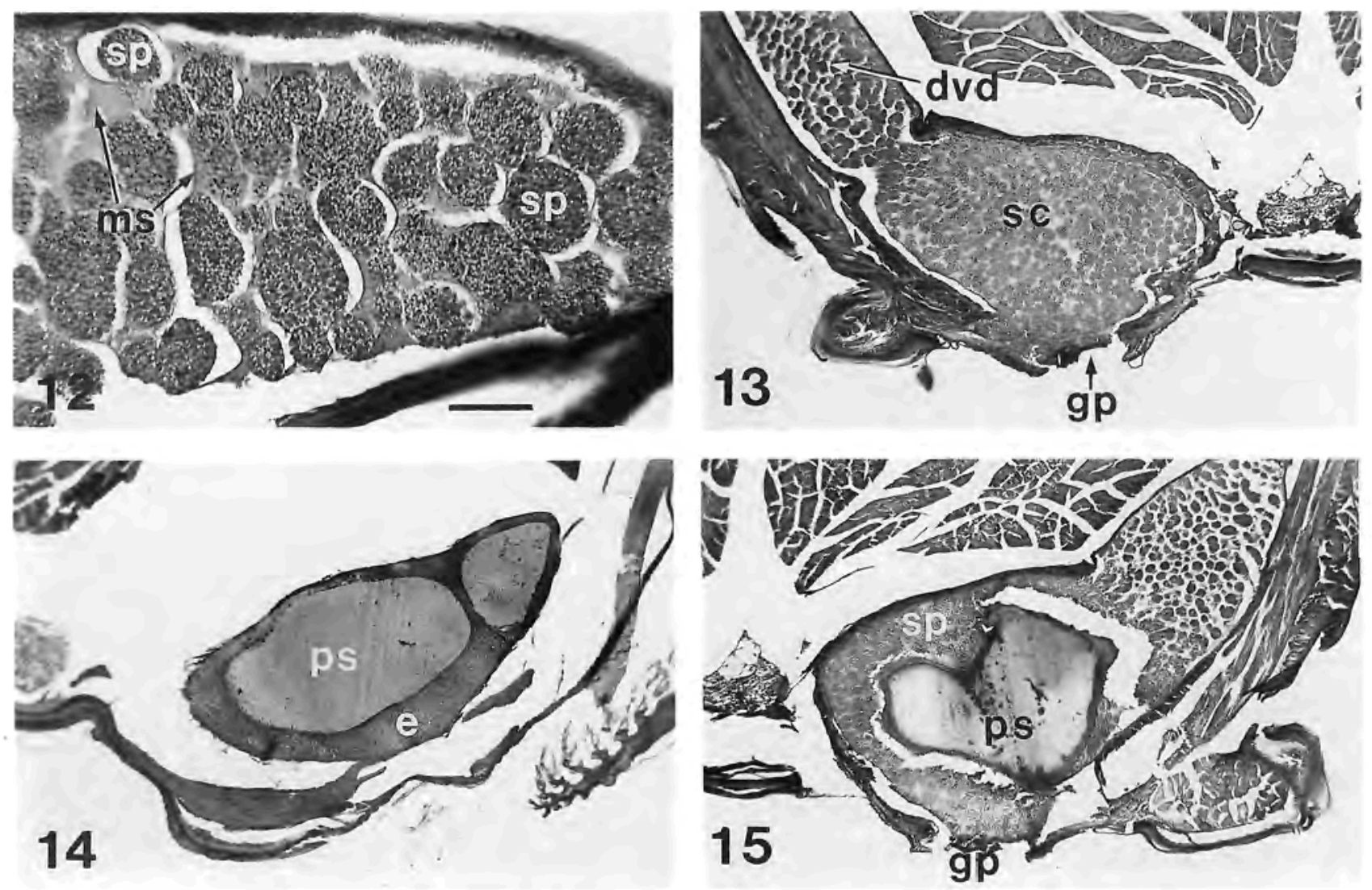

Figure 12. Longitudinal section through segment of distal vas deferens. Section was stretched by heating during preparation, separating groups of sperm (spermatophores) from surrounding MVD substance. ms, MVD substance; sp, spermatophores.

Figure 13. Cross section through spermatophore chamber (sc) of ejaculatory duct, left side, at level of gonopore (gp). dvd, distal vas deferens.

Figure 14. Cross section through plug substance chamber, posterior end, of right ejaculatory duct. e; epithelium; ps, plug substance.

Figure 15. Cross section through right ejaculatory duct near posterior end of gonopore. Note plug substance (ps) surrounded by spermatophores (sp). gp, gonopore. Scale bar in Figure 12 represents $300 \mu \mathrm{m}$ in Figure 12 and $2 \mathrm{~mm}$ in Figures 13-15.

seconds of emission, it becomes only weakly adhesive, and it changes from a viscous fluid to a soft, malleable, solid mass. It begins a change in transparency and color within seconds, becoming opaque and white within a few minutes. The gross appearance of the PSC material is, after some minutes of exposure to seawater, identical to the material, termed here "plug substance," which plugs and seals the median pocket and seminal receptacles of the female (see below).

\section{Disposition of sperm and plug substance in the inseminated female}

Modifications of the sternum of the penultimate (XIII) and ultimate (XIV) segments of the cephalothorax comprise the genital area, or thelycum, of the female. The external morphology of the thelycum can be best observed in recently molted, uninseminated females (Fig. 16). On sternite XIV, a pair of flaps (Fig. 16), separated by a longitudinal gap, form the floor of a space, the median pocket (Figs. 18-20). On sternite XIII is the undivided median protuberance, part of which extends posteriorly and dorsal to the sternite XIV flaps. In most inseminated females, the plug substance (PS) from the male can be seen protruding from the median pocket in the transverse gap between the median protuberance and the flaps, and from between the mesial margins of the latter (Figs. 17, 1820 ). The PS is quite hard in living females and firmly seals the thelycum flaps together. In contrast, in living or preserved uninseminated females, the flaps can be pulled back and moved quite easily. The PS in the median pocket of the female thelycum has similar staining properties as that 

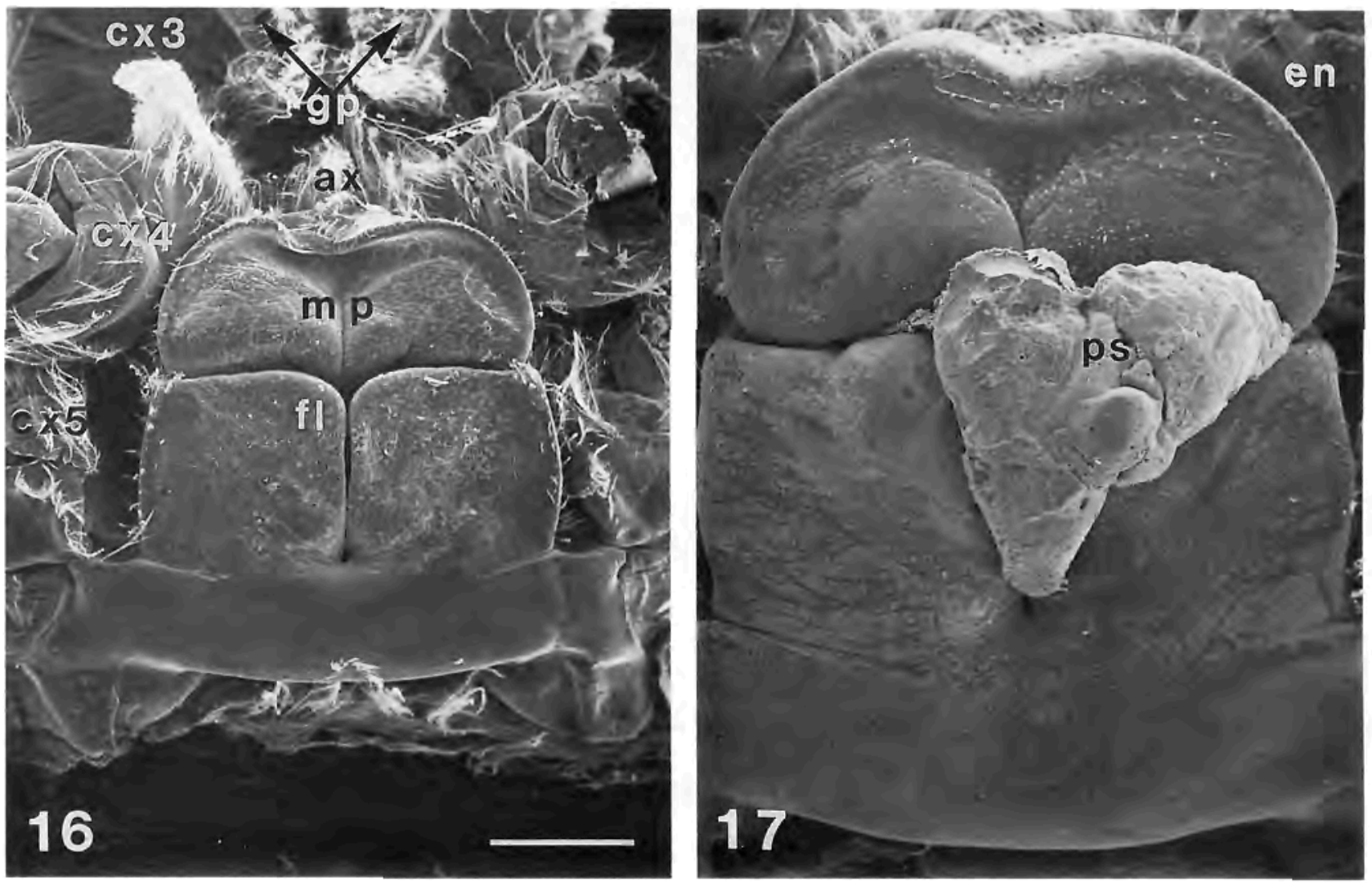

Figure 16. Ventral surface of posterior cephalothorax of an uninseminated female of Trachypenaeus similis, showing thelycum. ax, apex of median protuberance; cx3, cx4, cx5, coxae of third, four, and fifth pereiopods, respectively. fl, flap; gp, gonopores: $\mathrm{mp}$, median protuberance.

Figure 17. Thelycum of inseminated female, showing plug substance (ps) protruding from median pocket. en, endite of coxa of pereiopod 4. Scale bar in Figure 16 represents $590 \mu \mathrm{m}$ in Figure 16 and $421 \mu \mathrm{m}$ in Figure 17.

in the PSC of the male, as well as comparable physical properties such as hardness and homogeneity of texture in paraffin-carved material viewed with SEM (Figs. 11, 18-20). Examination of exuviae of inseminated females shows that PS remains in the median pocket from the time of insemination until the next molt, at which time it is cast off with the exuviae.

Inside the cephalothorax, dorsal to the thelycum, lie a pair of cuticular invaginations, the seminal receptacles, each with large posterior and smaller anteromesial and anterolateral lobes (Figs. 22-23). The posterior lobes are dorsal to sternite 14, while the anterior lobes lie dorsal and lateral to the median protuberance. Sections through the seminal receptacles showed no spermatophores but rather sperm in a solid mass. Within the sperm mass, small, irregular patches of material, identical in appearance and staining properties to that of the MVD substance of the male, were usually observed in sectioned material. Examination of exuviae show that sperm remaining in the receptacles, often in considerable quantity, are cast off with the cuticular lining of the receptacles when an inseminated female molts.
The opening into each seminal receptacle is a narrow slit between the anteromesial and posterior lobes that extends up to the anterolateral lobe as well. Each seminal receptacle slit (SRS) begins in the roof of the median pocket just posterior to the transverse gap between flaps and median protuberance (Fig. 20), extending anteriorly along the sides of the median protuberance up to about the level of the coxal endite (Fig. 17) of pereiopod 4. Sections through the posterior end of the SRS of inseminated females show that the borders of the SRS are separated but that the opening is stoppered with plug substance (Figs. 20, 21). More anteriorly, in the region just anterior to the transverse gap between flaps and median protuberance, the SRS appears functionally closed because its borders, the median protuberance on one side and a fold of the adjacent sternal wall on the other, are tightly pressed together (Figs. 24, 25). The borders of the SRS separate again near its anterior end so that the anterolateral lobe of the seminal receptacle is open to the exterior near the coxal endite of pereiopod 4 (Fig. 26). In serial sections through the genital area of several females, sperm were found outside 

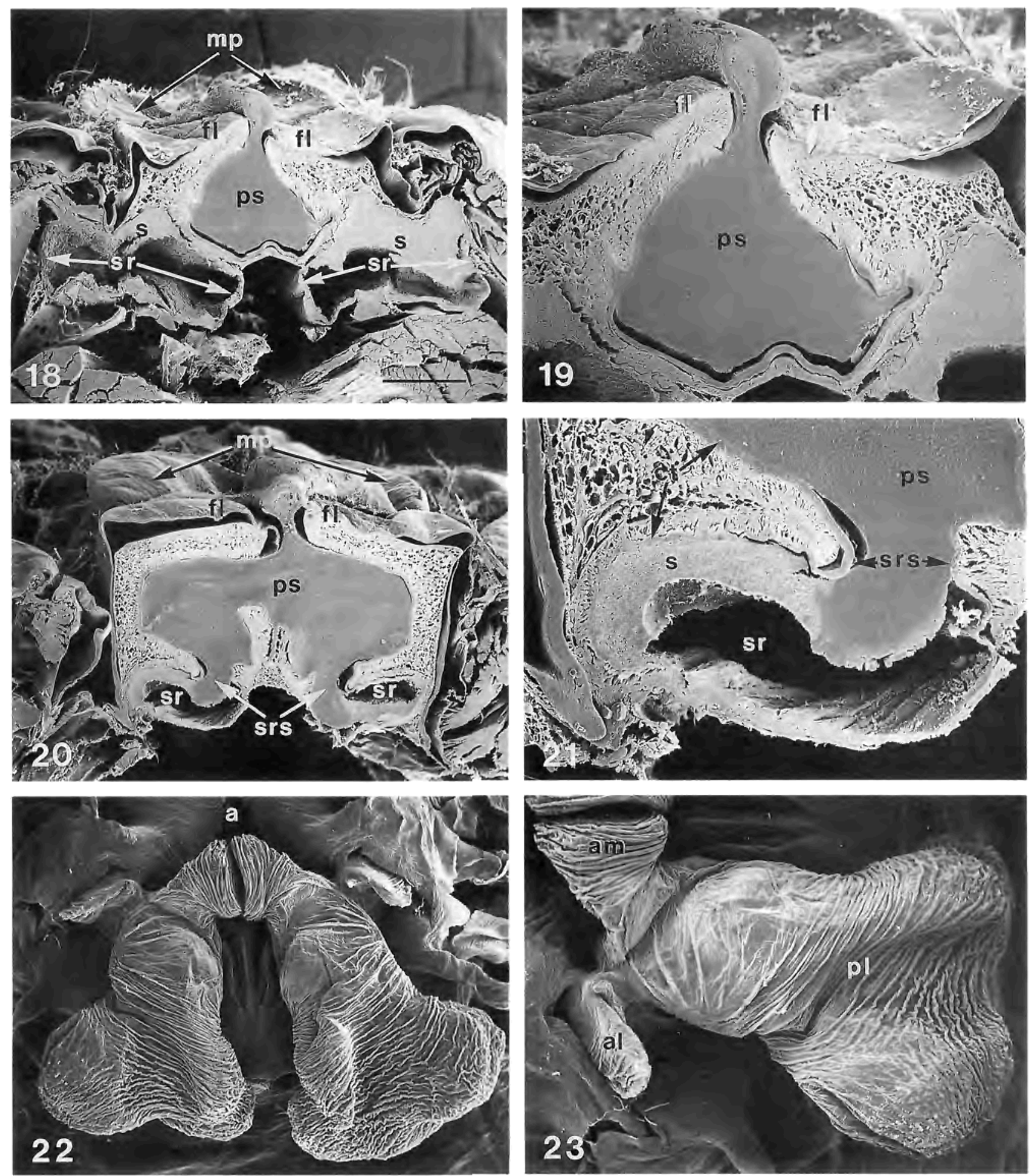

Figure 18. Cross section through thelycum of inseminated female of Trachypenaeus similis at approximately halfway between anterior and posterior ends of transverse slit between flaps (see Figures 16-17 for orientation). Section is viewed from posterior side of animal, ventral (external) surface up. Median pocket is filled with plug substance (ps) that protrudes from between flaps (fl) to exterior. Posterior lobes of seminal receptacles ( $\mathrm{sr}$, lateral extent indicated by arrows) inside the cephalothoracic cavity are partially filled with sperm (s). mp, median protuberance.

Figure 19. Higher magnification of median pocket filled with plug substance (ps) which protrudes to exterior between flaps (fl) of thelycum.

Figure 20. Cross section through thelycum of inseminated female just posterior to transverse gap between flaps ( $\mathrm{fl}$ ) and median protuberance (mp). Orientation same as that for Figure 18. Note plug substance (ps) intruding into each seminal receptacle (sr) from median pocket, plugging each receptacle's slit or opening (srs). 
of the seminal receptacles, anterior to the SRS, in the channel or groove (Fig. 27) on each side of the median protuberance up to its apex near the female gonopores (Fig. 16).

\section{Discussion}

The packaging of sperm into numerous small spermatophores, as described here in Trachypenaeus similis, is unusual for a penaeoid shrimp. In most species of penaeoids, a single large mass of sperm, surrounded by a variety of accessory materials, is emitted from each male gonopore during ejaculation (Heldt, 1938a, b; Malek and Bawab, 1974a, b; Pérez Farfante, 1975; Champion, 1987; Orsi Relini and Tunesi, 1987; Ro et al., 1990; Bauer and Cash, 1991; Bauer, 1991, Chow et al., 1991). In species with such large, complex spermatophores, the vas deferens is subdivided into two ducts, one containing sperm mass and surrounding capsular substance, the other with one or more accessory materials that serve to attach or seal the sperm mass on or in the thelycum of the female. In T. similis, as in other Trachypenaeus spp., the vas deferens is a simple undivided tube containing a single material (MVD substance) that participates in the formation of many small spermatophores. The "plug substance" of $T$. similis, appearing only in the ejaculatory duct, is not homologous to accessory materials produced in the median vasa deferentia of other penaeoid shrimps. Observations by Burkenroad (1934) indicate that males of another penaeid, Xiphocaris kroyeri (Heller), may have a similar system of many small spermatophores with a plug substance present in the ejaculatory duct, but the details of this system have not yet been described. Only males of the penaeoid genus Sicyonia have simpler reproductive tracts in which a simple mass of sperm in a fluid matrix is found in the vas deferens, is emitted from the gonopores, and is stored in the female seminal receptacles without any male accessory substances (Burkenroad, 1934; Bauer, 1991).

Ultrastructural studies on the vasa deferentia of a variety of male decapods have demonstrated the secretion of spermatophore and accessory substances by the epithelium of the vas deferens [majid crab Libinia emarginata Leach, Hinsch and Walker, 1974; lobster Homarus americanus H. Milne Edwards, Kooda-Cisco and Talbot, 1986; majid crab Chionoecetes opilio (O. Fabricius), Ben- inger et al., 1988; crayfish Cherax albidus, Talbot and Beach, 1989; Penaeus shrimps, Ro et al., 1990; Chow et al., 1991]. We did not study possible secretion of the material (MVD substance) that appears to form the pellicles of spermatophores in Trachypenaeus similis. Secretion of MVD substance might be revealed by ultrastructural studies on the epithelium of the proximal coils of the median vas deferens where this substance first appears.

Males of brachyuran crabs such as Carcinus maenas (Linnaeus), Callinectes sapidus Rathbun, Portunts sanguinolentus (Herbst), Chionoecetes opilio, and Geryon spp. produce many spermatophores of small size, as in Trachypenaeus similis. The epithelium of the vas deferens of these brachyurans secretes a substance or substances that, after intermixing into the sperm mass and surrounding groups of sperm, condenses into the spermatophore pellicle (Spalding, 1947; Cronin, 1947; Ryan, 1967; Beninger et al., 1988; Hinsch, 1988, 1991). Our observations in this study on isolation of packets of sperm by MVD substance suggest a comparable mechanism of spermatophore formation in $T$. similis. We observed peristaltic contractions in the median and distal portions of vasa deferentia excised from freshly sacrificed males, similar to observations made in other decapod species (Ryan, 1967; Ro et al.. 1990; suggested from vas deferens ultrastructure by Kooda-Cisco and Talbot, 1986; Talbot and Beach, 1989). Such contractions of the vas deferens wall might serve to intermix MVD substance with the sperm mass in spermatophore formation as well as move all duct contents more distally.

The sperm cells of Trachypenaeus similis are similar to those described for other penaeoid shrimps (Clark et al., 1984; Griffin et al., 1988; Felgenhauer and Abele, 1991) except for a novel structure, a long delicate but conspicuous filament on the end of the cell opposite the spike. The filaments were not only visible in sperm released from spermatophores but also apparent within sectioned vasa deferentia, indicating that the filaments were not artifacts nor results of any type of reaction of sperm to seawater.

The distribution of plug substance in the median pocket of the female thelycum, and its emission after the spermatophores in artificially ejaculated males, suggest alternative hypotheses on the mechanics of insemination in Trachypenaeus similis. One alternative we propose is that

Figure 21. Close-up of cross section through one seminal receptacle from Figure 20. Slit or opening (srs) to receptacle from median pocket is filled with plug substance (ps). Note that cuticle (ct) of median pocket (arrow towards upper right) is continuous with that (arrow towards lower left) of seminal receptacle (sr, empty part of lumen of receptacle). s, sperm mass with bits of darker MVD substance inside receptacle.

Figure 22. Dorsal view of left and right seminal receptacles inside cephalothozax. Internal organs and soft tissues were removed by treatment with $\mathrm{KOH}$. leaving only cuticular structures. a, anterior direction.

Figure 23. Close-up of left seminal receptacle from Figure 22, rotated $90^{\circ}$, al, anterolateral lobe; am, anteromesial lobe; pl, posterior lobe. Scale bar in Figure 18 represents $492 \mu \mathrm{m}$ in Figure $18,230 \mu \mathrm{m}$ in Figure 19, $402 \mu \mathrm{m}$ in Figure 20, $126 \mu \mathrm{m}$ in Figure 21, $466 \mu \mathrm{m}$ in Figure 22, and $300 \mu \mathrm{m}$ in Figure 23. 

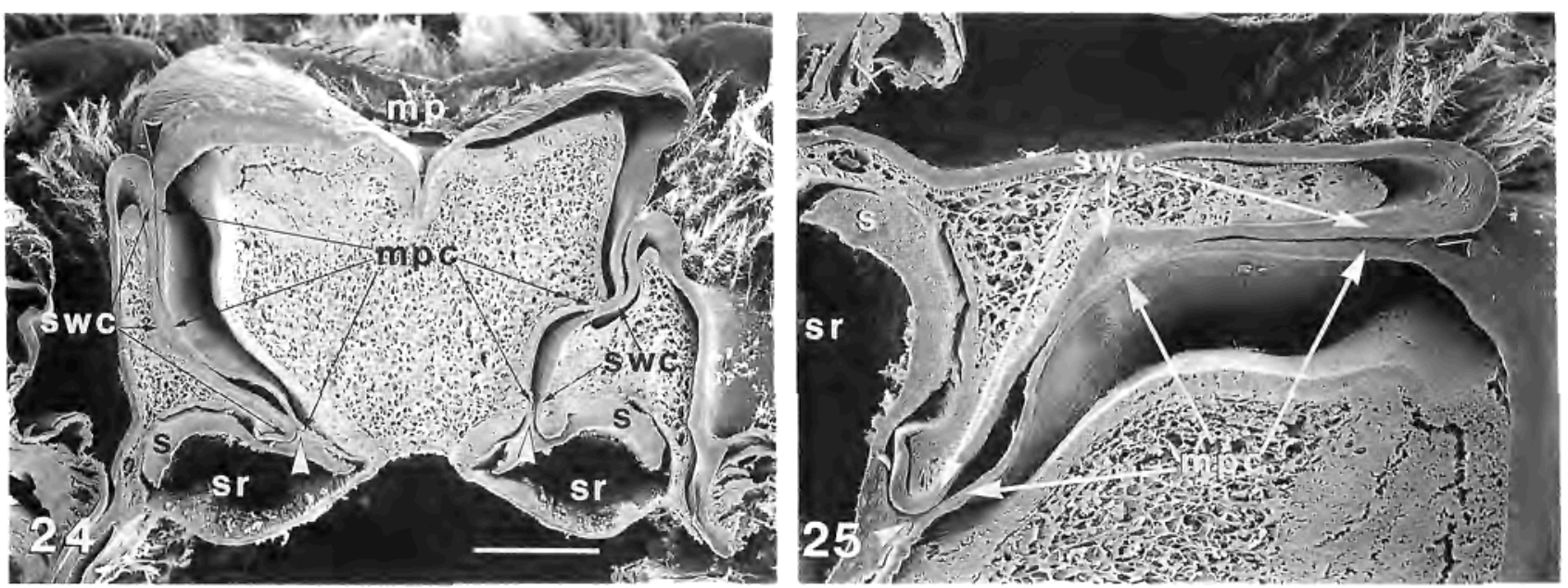

Figure 24. Cross section through median protuberance $(\mathrm{mp})$ just anterior to thelycum flaps and median pocket (same orientation as Figures 18 and 20). Unmarked black arrowheads point to locations on external surface which would be open to passageway leading to the slits or openings (unmarked white arrowheads) of seminal receptacles $(\mathrm{sr}$ ) if passageway were not blocked by abutting cuticles of median protuberance and adjoining sternal wall. mpc, cuticle of median protuberance; s, sperm mass; sr. lumen of seminal receptacle; swc. cuticle of sternal wall.

Figure 25. Close-up of blocked passageway between opening to seminal receptacle and external surface. Rotated $90^{\circ}$ clockwise from Figure 24, left side iright side of animal). Note bit of sperm mass trapped about midway (middle arrows of mpc and swc) along the closed passageway. Labels same as Figure 24. Scale bar in Figure 24 represents $385 \mu \mathrm{m}$ in Figure 24 and $179 \mu \mathrm{m}$ in Figure 25.

the spermatophores are introduced into the median pocket, followed by an injection of plug substance, directly from the male gonopore that is perhaps everted into a papilla during ejaculation. In this scenario, the plug substance would displace the spermatophores from the me- dian pocket (rupturing them in the process), would force the sperm mass into the posterior ends of the slits that open into the seminal receptacles, and would stopper these openings, preventing backflow and loss of sperm from the receptacles. Alternately, Burkenroad (1934) suggested that
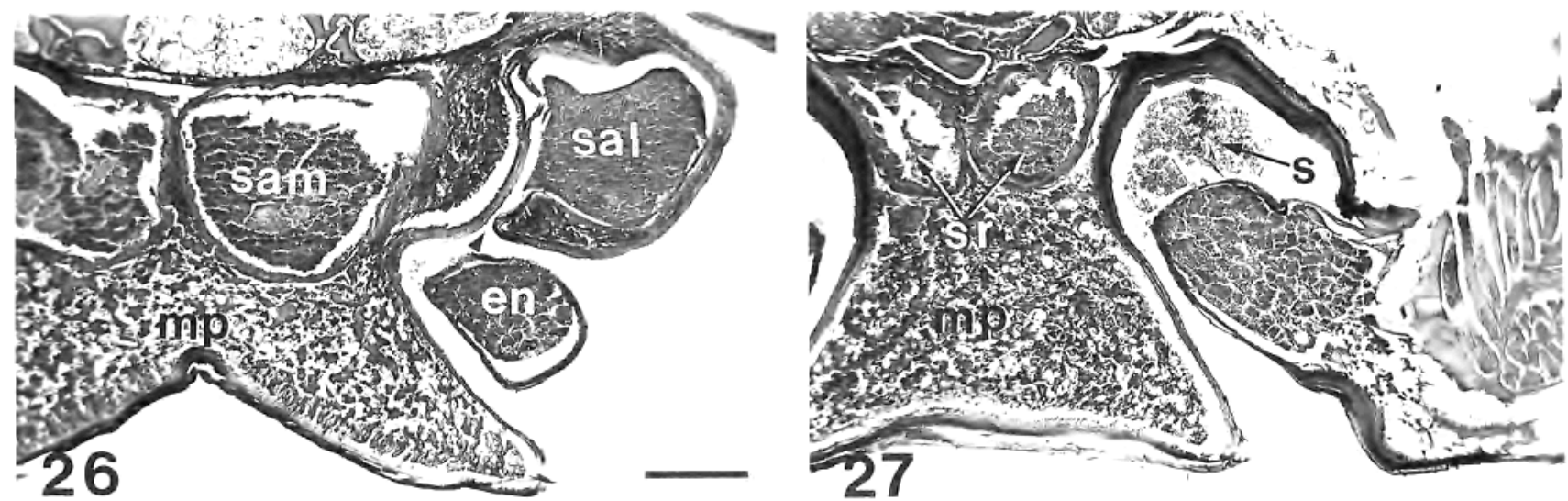

Figure 26. Cross section through median protuberance $(\mathrm{mp})$ and area just lateral on right side (section viewed from posterior, dorsal is up in micrograph). Note that opening (small arrowhead) from anterolateral lobe of right seminal receptacle is open to the exterior. en, section through coxal endite of pereiopod 4: sal. sperm mass inside anterolateral lobe; sam, sperm mass inside anteromesial lobe of right seminal receptacle.

Figure 27. Cross section through the median protuberance $(\mathrm{mp})$ near its apex. Same orientation as Figure 26. Note sperm (s) outside of seminal receptacles in channel between median protuberance and sternum lateral to it. sf, very anterior ends of anteromesial lobes of seminal receptacles, partially filled with sperm. Scale bar in Figure 26 represents $2 \mathrm{~mm}$ in Figures 26 and 27. 
the petasma, a semi-closed tubular structure on the male's first pleopods, might function as the injection apparatus, with each of its grooved horns inserting into one of the seminal receptacles during copulation. He hypothesized that spermatophores would first be deposited, and then the petasma would withdraw slightly and deposit the "sperm free secretion" or plug substance into the median pocket. It seems unlikely to us that plug substance, only slightly fluid when first ejaculated, hardening to a soft mass almost immediately, could flow through the petasma and out its narrow terminal channels.

In many vertebrates and invertebrates, hardened or coagulated male products ("mating or copulatory plugs") block the openings to the female reproductive tract after mating (Mann, 1984). Parker (1970) and Thornhill and Alcock (1983), citing examples of mating plugs in various insect species, suggested that one function of mating plugs is to prevent re-insemination of a female once it has mated. Mating plugs ("sperm plugs") have been described in a variety of brachyuran crabs by Hartnoll (1969), who suggested their major role was to prevent loss of sperm from receptacles after copulation. However, Diesel (1991) discussed their possible function as a paternity assurance mechanism in certain brachyurans. In Trachypenaeus similis, the male plug substance that blocks access to the seminal receptacles of the females may serve, in addition to preventing loss of sperm from the receptacles after copulation, as a mating plug precluding subsequent inseminations by other males. We have observed during artificial ejaculation of males that the amount of plug substance in and protruding from the median pocket of the female thelycum is approximately that emitted from one ejaculatory duct of one male.

Plug substance may also play an indirect but important role in sperm release from the seminal receptacles. During spawning and concomitant fertilization, which occur separately from mating and insemination in most penaeoids (Anderson et al., 1985; Pillai et al., 1988; Bauer, 1991), sperm being forced out of receptacles by whatever means would be prevented from flowing back out the wrong direction (into the median pocket) by the plug substance that stoppers the receptacle apertures. Sperm must leave the receptacles through what appears to be the only available exits, the openings from the anterolateral lobes of the receptacles. From these exits, sperm would enter the grooves on each side of the median protuberance, streaming forward to just below the gonopores where eggs would be emerging during spawning.

\section{Acknowledgments}

The senior author (R.T.B.) wishes to thank Dr. Isabel Pérez Farfante for the stimulating and useful discussions on the thelyca and seminal receptacles of Trachypenaeus spp. We wish to thank George Cantrell, captain of the R/V Bill Demoran out of the Gulf Coast Research Laboratory, for his skill and patience in trawling Trachypenaeus on our collecting trips to Horn Island, Mississippi. Our participation in cruises on the NOAA vessel R/V Oregon II was quite useful in collecting material used in this study. We thank Dr. Bruce Felgenhauer for alerting us to the polylysine technique used in preparing spermatophores for SEM. We also thank the anonymous reviewers of this manuscript for their helpful suggestions and comments. This research was supported by grants from the National Oceanographic and Atmospheric Administration's Louisiana Sea Grant Program (No. NA89AA-D-SG226) and the Louisiana Educational Quality Support Fund (1989-92-RD-A-20).

\section{Literature Cited}

Anderson, S. L., W. H. Clark, Jr., and E. S. Chang. 1985. Multiple spawning and molt synchrony in a free spawning shrimp (Sicyonia ingentis: Penacoidea). Biol. Bull. 168: 377-394.

Andrews, E. A. 1911. Sperm transfer in certain decapods. Proc U.S Natl. Mus. 39: 419-434.

Bauer, R. T. 1987. Stomatopod grooming behavior: functional morphology and amputation experiments in Gonodacty/us oerstedii. I. Crustaceun Biol. 7: 414-432.

Bauer, R. T. 1991. Sperm transfer and storage structures in penaeoid shrimps: a functional and phylogenetic perspective. Pp. 183-207 in Crustacean Sexual Biology, R. T. Bauer and J. W. Martin, eds. Columbia University Press, New York.

Bauer, R. T. 1992. Repetitive copulation and variable success of insemination in the marine shrimp Sicyonia dorsalis (Decapoda: Penaeoidea). J. Crustacean Biol. 12: 153-160.

Bauer, R. T., and C. E. Cash. 1991. Spermatophore structure and anatomy of the ejaculatory duct in Penaeus setifenis, $P$. duorarum, and $P$. aztecus (Crustacea: Decapoda): homologies and functional significance. Trans. Am. Microsc. Soc. 110: 144-162.

Beninger, P. G., R. W. Elner, T. P. Foyle, and P. H. Odense. 1988. Functional anatomy of the male reproductive system and the female spermatheca in the snow crab Chionoecetes onilio (O. Fabricius) (Decapoda: Majidac) and a hypothesis for fertilization. $J$ Crustacean Biol. 8: 322-331.

Burkenroad, M. D. 1934. The Penaeidea of Louisiana, with a discussion of their world relationships. Bull, Am. Mus. Nat, Hist. 68: $51-143$.

Champion, H. F. B. 1987. The functional anatomy of the male reproductive system in Penaens indicus. S. Afr. J. Zool. 22: 297-307.

Chow, S., M. M. Dougherty, W. J. Dougherty, and P. A. Sandifer. 1991. Spermatophore formation in the white shrimps Penaeus setiferus and P. vannamei. J. Crustacean Biol. 11: 201-216.

Clark, W. H., Jr., A. I. Yudin, F. J. Griffin, and S. Shigekawa. 1984. The control of gamete activation and fertilization in the marine Penaeidae, Sicyonia ingentis. Pp. 459-472 in Advances in Invertebrate Reproduction 3, W. Engels et al., eds. Elsevier Science Publishers B. V., Amsterdam.

Cronin, L. E. 1947. Anatomy and physiology of the male reproductive system of Callinectes sapidus Rathbun. J. Morphol. 81: 209-239.

Diesel, R. 1991. Sperm competition and the evolution of mating behavior in Brachyura, w:th special reference to spider crabs (Decapoda, Majidae). Pp. 145-163 in Crustacean Sexual Biology, R. T. Bauer and J. W. Martin, eds. Columbia University Press, New York.

Felgenhauer, B. E., and L. G. Abele. 1991. Morphological diversity of decapod spermatozoa. Pp. 322-341 in Crustacean Sexual Biology, 
R. T. Bauer and J. W. Martin, eds. Columbia University Press, New York.

Galigher, A. E., and E. N. Kozloff. 1971. Essentials of Practical Microtechnique. Lea \& Febiger, Philadelphia. $531 \mathrm{pp}$.

Griffin, F. J., K. Shigekawa, and W. H. Clark, Jr. 1988. Formation and structure of the acrosomal filament in the sperm of Sicyonia ingentis. J. Exp. Biol. 246: 94-102.

Hartnoll, R. G. 1969. Mating in the Brachyura. Crustaceana 16: 161181.

Heldt, J. H. 1938a. La réproduction chez les crustacés décapodes de la famille de pénéides. Ann. Inst. Oceanogr. 18: 31-206.

Heldt, J. H. 1938b. De l'appareil génital des Penaeidac. Relations morphologique entre spermatophore, thelycum et petasma. Travaux de la Siation Zoologique de Wimereux 13: 349-358.

Hinsch, G. W. 1988. Ultrastructure of the sperm and spermatophores of the golden crab Geryon fenneri and a closely related species, the red crab G. quinquedens, from the eastern Gulf of Mexico. J. Crustacean Biol. 8: 340-345.

Hinsch, G. W. 1991. Structure and chemical content of the spermatophores and seminal fluid of reptantian decapods. Pp. 290-307 in Crustacean Sexual Biolog:, R. T. Bauer and J. W. Martin, eds. Columbia University Press, New York.

Hinsch, G. W., and M. H. Walker. 1974. The vas deferens of the spider crab, Libinia emarginata. J. Morphol. 143: 1-20.

Hudinaga, M. 1941. Reproduction, development, and rearing of Penaeus japonicus. Jpn. J. Zool. 10: 305-393.

Kooda-Cisco, M., and P. Talbot. 1986. Ultrastructure and role of the lobster vas deferens in spermatophore formation: the proximal segment. J. Morphol. 188: 91-104.

Kubo, I. 1949. Studies on penaeids of Japanese and its adjacent waters. J. Tokyo Coll. Fish. 36: 1-467.

Malek, S. R. A., and F. M. Bawab. 1974a. The formation of the spermatophore in Penaeus kerathurus (Forskål. 1775) (Decapoda: Penaeidae). I. The initial formation of a sperm mass. Crustaceana 26: 273-285.

Malek, S. R. A., and F. M. Bawab. 1974b. The formation of the spermatophore in Penaeus kerathurus (Forskäl, 1775) (Decapoda: Penaeidae). II. The deposition of the main layers of the body and of the wing. Crustaceana 27: 73-83.

Mann, T. 1984. Spermatophores. Spring-Verlag, Berlin. 240 pp.
Mazia, D., G. Schatten, and W. Sale. 1975. Adhesion of cells to surfaces coated with polylysine. J. Cell Biol. 66: 198-200.

Orsi Relini, L., and L. Tunesi. 1987. The structure of the spermatophore in Aristeus antennatus (Risso, 1816). Invest. Pesq. 51(Supl. 1): 461470.

Parker, G. A. 1970. Sperm competition and its evolutionary consequences in the insects. Biol. Rev. Camb. Philos. Soc. 45: 525-567.

Pérez Farfante, I. 1971. A key to the American Pacific shrimps of the genus Trachypenaeus (Decapoda: Penaeidae), with the description of a new species. U.S. Natl. Mar. Fish. Serv. Fish. Bull. 69: 635-646.

Pérez. Farfante, I. 1975. Spermatophores and thelyca of the American white shrimps, genus Penaeus, subgenus Litopenaeus. U.S. Natl. Mar. Fish. Serv. Fish. Bull. 73: 463-486.

Pérez Farfante, I. 1982. The geminate shrimp species Parapenaeus longirostris and P. polirus (Crustacea: Decapoda: Penaeoidea). Quad. Lab. Tecn. Pesca Ancona 3: 187-205.

Pérez Farfante, 1. 1985. The rock shrimp genus Sicyonia (Crustacea: Decapoda: Penaeoidea) in the eastern Pacific. U.S. Natl. Mar. Fish. Serv. Fish. Bull. 83: 1-78.

Pillai, M. C., F. J. Griffin, and W. H. Clark, Jr. 1988. Induced spawning of the decapod crustacean Sicyonia ingentis. Biol. Bull. 174: 181185.

Ro, S., P. Talbot, J. Leung-Trujillo, and A. L. Lawrence. 1990. Structure and function of the vas deferens in the shrimp Penaeus setiferus: segments 1-3. J. Crustacean Biol. 10: 455-468.

Ryan, E. P. 1967. Structure and function of the reproductive system of the crab Portunus sanguinolentus (Herbst) (Brachyura: Portunidae). I. The male system. Proc. Symp. Crustacea, Mar. Biol. Assoc. India 2: 506-521.

Shaw, B. L., and H. I. Battle. 1957. The gross and microscopic anatomy of the digestive tract of the oyster Crassostrea virginica (Gmelin). Can. J. Zool. 35: 325-347.

Spalding, J. F. 1942. The nature and formation of the spermatophore and sperm plug in Carcinus maenas. Q. J. Micruse: Sti. 83: 399422.

Talbot, P., and D. Beach. 1989. Role of the vas deferens in the formation of the spermatophore of the crayfish (Cherax). J. Crustacean Biol. 9: 9-24.

Thornhill, R., and J. Alcock. 1983. The Evolution of Insect Mating Systems. Harvard University Press, Cambridge, Massachusetts. 547 pp. 